\title{
PROPOSIÇÃO DE ARTEFATO TECNOLÓGICO BASEADO EM IOT NA GESTÃO HÍDRICA
}

\author{
Francisco André Moreira de Lima, Ricardo Marciano dos Santos, Mariana Akemi Terada, \\ Vinícius Marques da Silva Ferreira, Jones Marciano dos Santos e Fernando Neves da Silva \\ LAMAE-HCTE-Universidade Federal do Rio de Janeiro \\ Avenida Atos da Silveira Ramos, 274 - Cidade Universitária, Brasil
}

\begin{abstract}
RESUMO
O objetivo deste trabalho é desenvolver um sistema de automação na gestão dos recursos hídricos em ambientes que exigem irrigação periódica e sistemática, de forma a promover condições ideais de cultivo sem desperdícios e criar uma maior autonomia dos recursos humanos na gestão deste processo, aplicando hardware de baixo custo e tecnologia de software. Com a necessidade de melhorias na gestão da água e economia de recursos humanos no processo, surgiu a demanda pelo desenvolvimento de um sistema que permita a gestão do processo de irrigação onde são utilizados somente os recursos necessários, otimizando a quantidade de água utilizada, e dos recursos humanos, porque, com a automação e monitoramento das variáveis ambientais, a intercessão humana necessária é mínima. Com a implantação deste sistema, espera-se que o manejo da irrigação se torne mais econômico e eficiente, contribuindo para uma tendência mundial, de uso mais eficiente de um recurso cada vez mais escasso, como a água, com baixo investimento, gerando economia e eficiência.
\end{abstract}

\section{PALAVRAS-CHAVE}

Arduino, IOT, IHM, Sensor

\section{INTRODUÇÃ̃}

A automação de atividades que envolvem a utilização de água em seu processo pode representar uma contribuição importante para um correto e preciso uso de água, com o objetivo de evitar desperdício e ao mesmo tempo manter as condições ideais de umidade, adequada ao processo. A implementação da automação de processos nas lavouras, jardins e áreas onde ocorre a necessidade de irrigação sistemática pode proporcionar um uso preciso de água, pois o sistema pode ser ajustado para cada tipo de cultivo, respeitando as características e necessidades particulares de cada vegetal, mas aliado a isso, temos também a economia em recursos humanos, uma vez que, o processo passa a ser automático.

"Economizar água não é mais só um hábito saudável. Atualmente, é uma grande responsabilidade com o futuro. Se não mudarmos nossos hábitos, a escassez de água para o consumo vai nos afetar seriamente." (Dinis, 2013)

"A economia de água na agricultura é possível tanto por meio de métodos de irrigação alternativos e uso de novas tecnologias como pelo reaproveitamento e controle do uso dos recursos hídricos." (Pena, 2015) Neste cenário a tecnologia surge como importante fator e fazendo o papel de interface entre humano e computador (IHC), é um campo multidisciplinar, pois contempla áreas da computação e ciência cognitiva, especificamente o processo de design, a concepção, implementação e avaliação de sistemas interativos no contexto da tarefa e trabalho do usuário. (Santos, 2020), assim, neste trabalho a IHM, tem papel fundamental.

A automação surge como um dos recursos fundamentais, a automação hídrica se apresenta como um novo mercado com potenciais ainda em desenvolvimento, colaborando na gestão hídrica e no manejo de processos que demandem recursos hídricos nos processos, gerando economia e precisão na manutenção das condições ideais ao cultivo neste contexto a utilização de recursos da IOT Internet das coisas (em inglês Internet of Things - IoT é hoje elemento de grande destaque, o termo Internt of Things foi referido pela primeira vez por Kevin Ashton em 1999, no contexto da gestão da cadeia de abastecimento (Ashton, 1999). 
A IoT foi desenvolvida para tornar mais prático o controle os outros equipamentos eletrônicos através de sistemas de softwares desenvolvidos para fazer determinadas ações ou comandos que são realizados por intermédio do uso da internet.

Um exemplo prático e funcional de utilização desse artefato, é o uso de água na irrigação de um determinado cultivo, usando como base as características do vegetal cultivado, do solo e das condições climáticas, através dos dados gerados pelos sensores, possibilitando a tomada de decisão do sistema, já ajustado para esse cultivo específico, utilizando os recursos hídricos estritamente necessários para a manutenção das condições ideais de cultivo, e com um custo extremamente baixo.

\section{METODOLOGIA}

O projeto apresenta três divisões básicas em seu desenvolvimento: software, interface humano computador e eletrônica. Os recursos de software empregados no projeto estão divididos em duas partes, o software que é executado no Arduíno desenvolvido basicamente em linguagens de programação $\mathrm{C} / \mathrm{C}++$ e a interface com o cliente desenvolvida em linguagens Web como Hypertext Markup Language (HTML), CSS e PHP, banco de dados Sql e Frameworks como Bootstrap, Ajax, JQuery.

Os recursos de interface humano computador, que foram embarcados no Arduíno, um servidor HTTP concomitante a um cliente HTTP, para que seja viável a troca de informações com a rede, utilizando assim, o protocolo HTTP, por questões de limitações da plataforma e para expandir os recursos de comunicação foram empregados também, recursos que o uso dos sockets e interrupções de hardware proporcionam.

No desenvolvimento do software que é embarcado na placa microprocessadora do Arduíno, a escolha pelo Arduino, foi por conta de sua simplicidade de utilização e a ampla disponibilidade das bibliotecas necessárias já embutidas na IDE, mantendo-se sempre atualizada as novas tecnologias. A figura 1 exibe a placa prototificadora ARDUÍNO.

Arduino é uma placa de prototipagem eletrônica de código aberto, o projeto, surgido na cidade de Ivrea, na Itália, em 2005, inclui hardware e software livre e visa oferecer ferramentas adaptáveis e de baixo custo para a criação de projetos interativos de diversas ordens. A base do Arduino é justamente a ideia do "faça você mesmo", (Santos, 2020)

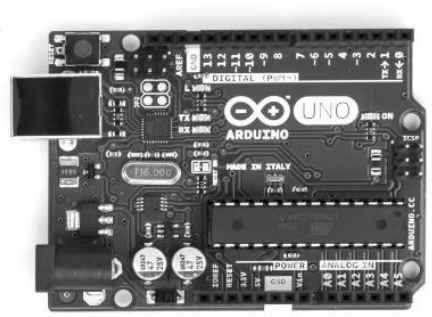

Figura 1. Placa de prototipagem Arduino utilizada no trabalho. Fonte: Arduino.cc

Além da plataforma Arduino Uno R3, foram utilizados outros dispositivos como: Shield ethernet utilizado para realizar a troca de dados e informações com a rede e com o banco de dados. O sensor de temperatura e umidade dht22, foi contemplado na intenção de executar o monitoramento e das condições do ambiente. $\mathrm{O}$ sensor de pressão atmosférica bmp foi utilizado para aferir pressão. O sensor de umidade do solo, tem a função de detectar as variações de umidade no solo, quando o solo está seco, a saída do sensor fica em estado alto e quando está úmido, a saída do sensor fica em estado baixo e por fim, o módulo relé, que quando o dispositivo recebe os dados oriundo dos sensores, realiza uma análise com base nos limites ajustados na interface de controle e dependendo dos resultados, se houver a necessidade acionará esse módulo relé e ligará um sistema de irrigação até que o solo volte a ter as condições consideradas ideais. Todos os dispositivos são apresentados respectivamente apresentados na figura 2. 


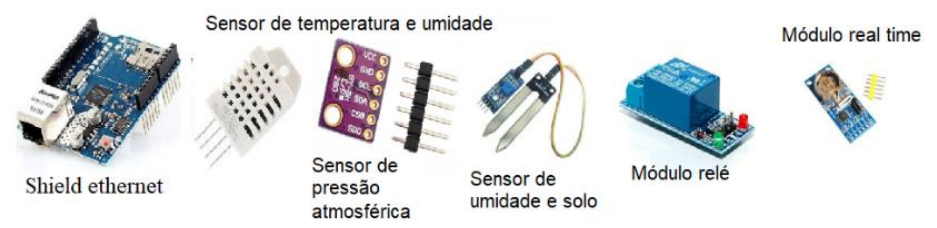

Figura 2. Shield e sensores utilizados no experimento

\subsection{Fluxo de Funcionamento do Protótipo}

O sistema utilizará como meio de transmissão de dados uma rede ethernet cabeada, com o intuito de simplificação do protótipo, mas poderá ser substituída facilmente por uma tecnologia wiffi ou rádio, sendo necessário para isso somente a troca da interface de comunicação. A figura 3 ilustra um esquema da comunicação e transferência de dados no sistema, a figura 12 exibe o esquema. inicialmente foi desenvolvido o software de controle dos sensores e do Arduíno Uno, implementando a leitura dos diversos sensores disponíveis no sistema e disponibilizando esses dados através de um servidor HTTP, o qual recebe as requisições vindas de um browser e gera a resposta adequada com esses dados, além da disponibilização desses dados na rede o software monitora à todo o tempo os dados coletados e caso as informações, após análise, apresentarem a necessidade de uma intervenção do sistema, como a irrigação do solo, isso ocorre automaticamente. Esse software embarcado na placa não faz a interface diretamente com o usuário, ele responde as requisições de um browser, através de um cabeçalho HTTP contendo as informações dos dados coletados, para otimizar esse envio os dados foram codificados em formato JSON que é anexado ao cabeçalho da resposta.

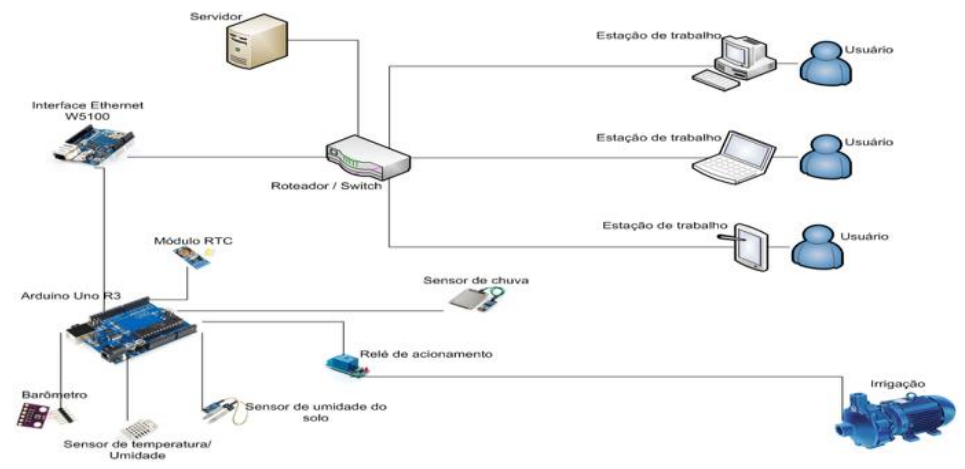

Figura 3. Esquema do protótipo

O dispositivo ao coletar os dados dos sensores realiza a persistência das informações em um banco de dados SQL, contendo os valores medidos, data e hora da medição, dados que são disponibilizados para consulta na interface Web do sistema, esse processo acontece da seguinte forma: o dispositivo realiza a leitura dos sensores e envia as informações a um arquivo PHP que realiza a persistência dos dados. Com a necessidade de realizar várias funções em paralelo, o que não é comum na arquitetura Arduíno, foi necessário a utilização de um artifício, as interrupções por Timer, conseguindo assim um pseudoparalelismo viabilizando todas as funções necessárias.

Foi utilizado no projeto um Shield Ethernet W5100, para sua implementação são necessárias as biblioteca ethernet.h e SPI.h, como dito anteriormente essa comunicação é realizada pelo protocolo HTTP, onde uma mensagem é disparada pelo cliente e recebida pelo servidor HTTP do Arduíno. É criado um servidor HTTP que recebe as requisições http vindas de um Browser e decodifica os dados. Nesse mesmo ponto criamos também um cliente http que realiza requisições a servidores externos, fazendo assim a troca de dados com o meio externo. 


\section{CONCLUSÃO}

Esta trabalho teve como enfoque a relação entre software e hardware e as possibilidades criativas quando ultrapassamos os limites estipulados pelos dispositivos de mercado, buscando o desenvolvimento e a colaboração dos analistas de sistemas e desenvolvedores na área de IOT, em ampla expansão e cada vez mais presente na sociedade. Criando soluções viáveis e de baixo custo para auxílio de atividades que hoje, ainda sofrem carência de dispositivos tecnológicos e pesquisas. A escolha do tema ligado ao meio ambiente não foi aleatório, A prototipagem se mostrou como uma técnica pouco aplicada pelos desenvolvedores de soluções nesse objetivo, podemos aprimorar, e muito, as técnicas de manejo e produção, aplicando pesquisas e dispositivos especialmente desenvolvidos para esse fim.

A possibilidade da união de desenvolvimento de software e eletrônica, ampliou exponencialmente as possibilidade de criação, unindo conhecimentos em programação, eletrônica, redes, comunicação diretamente ligados ao conceito de IOT - Internet of Things tornando nossos dispositivos cada vez mais inteligentes e úteis.

\section{REFERÊNCIAS}

Dinis, T. B. 2013.Economia de água.. Data de acesso em 10 de junho de 2019.

Dmitruk, H. B, 2001. Cadernos metodológicos: diretrizes da metodologia científica. Argos, Chapecó.

Ministério de Meio Ambiente, Secretaria Nacional de Recursos Hídricos, 1999. Politica Nacional de Recursos Hídricos,Brasília.

Pena, R. F. 2019. Geografia Ambiental e da Natureza. Acesso em 14 de Junho de 2019, disponível em Mundo da Educação: Data de acesso, 14 de Junho de 2019.

Santos, R.M. 2020, 'Proposição de um modelo de interação humano-computador baseado em lógica fuzzy para aferição de dados biofísicos', tese de Doutorado, Universidade Federal do Rio de Janeiro, Rio de Janeiro. 